\title{
Spatial prediction of soil moisture content using multiple-linear regressions in a gully catchment of the Loess Plateau, China
}

\author{
Y. Qiu ${ }^{\text {a,b, } * \text {, B. Fu }}{ }^{\mathrm{c}}$, J. Wang ${ }^{\mathrm{d}}$, L. Chen ${ }^{\mathrm{c}}$, Q. Meng ${ }^{\mathrm{e}}$, Y. Zhang ${ }^{\mathrm{a}, \mathrm{b}}$ \\ a School of Geography, Beijing Normal University, 19 Xinjiekouwai Street, Beijing 100875, PR China \\ ${ }^{\mathrm{b}}$ School of Forestry and Environmental Studies, Yale University, New Haven, CT 06511, USA \\ ' State Key Laboratory of Urban and Regional Ecology, Research Center for Eco-Environmental Sciences, Chinese Academy of Sciences, Beijing 100085, PR China \\ ${ }^{\mathrm{d}}$ Land Consolidation and Rehabilitation Center, Chinese Ministry of Land and Resources, Beijing 100035, PR China \\ e Academy of Forest Inventory and Planning, Chinese State Forestry Administration, Beijing 100055, PR China
}

\section{A R T I C L E I N F O}

\section{Article history:}

Received 5 July 2007

Received in revised form

1 March 2009

Accepted 4 August 2009

Available online 20 September 2009

\section{Keywords:}

DCA

Enter-method regression

Land use type

Model evaluation measures

PCA

Stepwise-method regression

Topographical indices

\begin{abstract}
A B S T R A C T
Spatial predictions of soil moisture content in arid lands are necessary for soil survey, land evaluation, hydrological modeling, land use planning and sustainable land use. Multiple-linear regression models with land use and terrain indices were developed to spatially predict soil moisture using six methods. The performance of six models was evaluated using 13 indices based on biweekly-measurement of soil moisture on 81 plots in the Loess Plateau, China. All 13 evaluation-indices gave similar results for the six methods in terms of goodness of fit from summary statistics indices, optimum from correlation-based indices, precision from absolute error indices, outlier from relativeerror indices and cost-benefit from information criteria. The with-attributes group model was superior to the other group models, and the principal components analysis based group model was better than the detrended correspondence analysis based group model. Within each group model, the models using enter-method were better than those using stepwise-method. The generalized multiple-linear regression models were the best in terms of goodness of fit, optimum, precision and outlier, and it can provide accurate information for soil properties analysis and for soil erosion modeling. The stepwise multiple-linear regression models were the most effective and economical, and can provide helpful information for land quality evaluation and land use planning.
\end{abstract}

(c) 2009 Elsevier Ltd. All rights reserved.

\section{Introduction}

Spatial predictions of soil characteristics (e.g. soil moisture content) across the landscape, preferably with a stated accuracy and precision are necessary for several applications: 1) parametric soil and land survey (McKenzie and Austin, 1993); 2) soil and land evaluation for sustainable use (Fu and Gulinck, 1994; Fu, 1991; Fu et al., 2000); 3) specific farm planning and management (Lark, 1999; Odeh et al., 1994); 4) hydrologic modeling, soil erosion modeling and watershed management (Hessel et al., 2003; Western et al., 1999).

There are several ways to predict soil moisture content, such as using local soil moisture classifications (Webster and Butler, 1976); direct interpolation of data from field sites using e.g. kriging (Wang et al., 2001); and environmental correlation using methods such as regression (McKenzie and Ryan, 1999). Combinations of approaches

\footnotetext{
* Corresponding author. Tel.: +86 10 58807472x1243; fax: +86 1058806955.

E-mail address: qiuyang69@263.net (Y. Qiu).
}

are also possible, such as co-kriging or kriging with regression (Knotters et al., 1995).

If soil moisture classifications are used, it is assumed that soil moisture of sampled sites applies to a complete mapping unit (Grayson and Western, 1998). In some landscapes, this may be appropriate, but in others, this assumption may fail (Webster and Butler, 1976) due to high spatial variation in soil moisture content across the landscape. This is for example the case on the Loess Plateau (Fu, 1989; Fu and Chen, 2000; Qiu et al., 2001).

While powerful geostatistical techniques exist for optimum direct interpolation of soil moisture from sample grids (Stein et al., 1988; Western et al., 1998; Yates and Warrick, 1987), these are only appropriate when areas are intensively sampled and when there are few, if any, major discontinuities (Webster, 1985). However, high spatial and temporal variability in soil moisture content results in expensive and inefficient surveys, and thus prevents the adoption of interpolation and surface fitting methods. "The spatial and temporal dimensions of soil moisture present real and difficult challenges for the interpretation of these data" (Steele et al., 2005: P93). Especially in the Loess Plateau, this interpolation method is 
difficult to apply for the spatial prediction of soil moisture because the soil moisture shows significant spatial variation due to fragmented topography (Wang et al., 2001). There is a need to develop methods for predicting soil moisture content which make the best possible use of all ancillary information, particularly that which is relatively inexpensive to obtain (Lark, 1999; Moore et al., 1993), especially in the Loess Plateau (Qiu et al., 2001).

Recent studies using linear models, particularly multi-linear regression models, have revealed the validity of predicting a soil property from surrogates or easy-to-measure morphological properties (Brubaker et al., 1994; McKenzie and MacLeod, 1989; McKenzie and Ryan, 1999; McKenzie et al., 1991; Manrique et al., 1991; Odeh et al., 1994). Stepwise regression (including a combination of forward stepwise and backward elimination procedures) has also been applied to identify only those predictive attributes that significantly improved the regression at given level (Hontoria et al., 1999; McKenzie and Austin, 1993; Moore et al., 1993; Wotling et al., 2000).

However, the more readily observed environmental properties can be complex and the data types are diverse. The classical approach of "dummy" variables was used for qualitative variables (Hontoria et al., 1999; Montgomery et al., 2006). A class of regression models known as generalized linear models (GLMs) can provide a framework that integrates the predictor data types including numeric data and categorical data (binary, ordinal and nominal data) (Mckenzie et al., 1991; Mckenzie and MacLeod, 1989; Manrique et al., 1991; Moore et al., 1993). In other studies, multiplevariable analysis on exploratory data has been reported when large numbers of variables are involved (McKenzie and Austin, 1993). In such situations, principal component analysis (PCA), has been applied to simplify the complexity of linear relations between environmental variables (Camdevyren et al., 2005; Odeh et al., 1991; Parinet et al., 2004). Although these linear methods may be successful, a nonlinear transformation such as detrended correspondence analysis (DCA) used in the field of plant ecology has not been applied in soil research (Qiu and Zhang, 1999; Ter Braak, 1988). These methods could be applied to the spatial prediction of soil moisture content.

The objective of this paper is (a) to analyze the environmental properties with correlation analysis, principle component analysis and detrended correspondence analysis in order to reveal the correlation and the main gradients in environmental attributes of soil moisture, (b) to develop multiple-linear regression models using six methods to predict soil moisture content across five soil depths and 10 sampling occasions, and (c) to compare and evaluate these six methods to determine the best prediction models.

The six methods used in this study can be grouped into three groups according to the independent variables used in the regression, and each group is split into two types based on the regression methods (Appendix 1, electronic version). The first group models, namely with-attribute group models, are multiple-linear regressions models with environmental attributes, including two regression methods (i.e. enter-method and stepwise-method). (1) Generalized multiple-linear regression models with environmental variables (GMLRMs), in which all the environmental variables are introduced into models directly, regardless of the correlation among variables; and (2) Stepwise multiple-linear regression models with environmental variables (SMLRMs), in which only significant variables are brought into models. The second group models, PCA-based group models, are regressions following a linear transformation of environmental variables by PCA, and also included two regression methods (i.e. enter-method and stepwisemethod). (3) Multiple-linear regression models with PCA axes on environmental attributes using the enter-method (PCA-EMLRMs) in which all the first four axes of PCA are entered into the regressions; and (4) multiple-linear regression models with PCA axes using stepwise-method (PCA-SMLRMs), in which only significant axes of PCA are selected into regressions. The last group models, DCA-based group models, are regressions following a non-linear transformation of environmental attributes by DCA. This group includes the same two regression methods (enter- and stepwisemethod). (5) Multiple-linear regression models with DCA axes on environmental attributes using the enter-method (DCA-EMLRMs) in which all the first four DCA axes are entered into the regressions; and (6) multiple-linear regression models with DCA axes using the stepwise-method (DCA-SMLRMs) in which only significant axes are entered into models.

\section{Materials and methods}

\subsection{Description of study area}

The Da Nangou catchment $\left(36^{\circ} 53^{\prime} \mathrm{N}, 109^{\circ} 17^{\prime} \mathrm{E}\right)$ is situated on the center of the Loess Plateau in northern Shaanxi province, P.R. China. The catchment is $3.5 \mathrm{~km}^{2}$ and ranges in altitude between 1000 and $1350 \mathrm{~m}$. Within the study area, there is significant topographic variability with typical loess hills and gully surface shapes (Fu and Chen, 2000). Due to long-term human activity, natural vegetation has been destroyed. The six major land use types are cropland, fallow land, wasteland, shrub land, orchard, intercropping land and woodland. These land uses form mosaic patterns (Wang et al., 2001). Crops are mainly potato (Solanum tuberosum L.), Soybean (Glycine max (L.) Merr.), maize (Zea mays L.), buckwheat (Fagopyrum esculentum Moench) and millet (Panicum miliaceum L.). Locust trees (Robinia pseudoacacia L.) dominate the anthropogenic forests. Annuals such as sweet wormwood (Artemisia annua L.), annual fleabane (Erigeron annuus Pers.) and sandy needle grass (Stipa glareosa p. Smirn) are the main species in grassland. Littleleaf peashrub (caragana microphylla) in shrub land and apple tree (Malus pumila Mill.) in orchard are the most common species in these land use types. Fallow land results from cultivated plots that were abandoned two and three years ago (Qiu et al., 2001).

This region has a semiarid continental climate with an average annual temperature of $8.8^{\circ} \mathrm{C}$. Monthly mean temperature ranges from $22.5^{\circ} \mathrm{C}$ in July to $-7^{\circ} \mathrm{C}$ in January. Average annual precipitation is $562 \mathrm{~mm}$ with great interannual variability and 60 percent of the rainfall falls between July and September. There are 159 frostfree days and an average of $2415 \mathrm{~h}$ of sunshine each year ( $\mathrm{Fu}$ and Gulinck, 1994).

The soils, developing on wind-accumulated loess parent material, are $50-80 \mathrm{~m}$ thick on average. No distinct B-horizon is developed in the soil profile. Active soil moisture change also occurs in deeper soil layers due to the relatively high permeability of the soil. Thus, from a runoff process perspective, soil moisture in the deeper layers has also important influence. The most common soil in the catchment is loessial with silt content ranging from $64 \%$ to $73 \%$ and clay content varying from $17 \%$ to $20 \%$. The soil is weakly resistant to erosion ( $\mathrm{Fu}, 1989)$. The erosion rate is extreme high at about $10,000-12,000$ ton $\mathrm{km}^{-2} \mathrm{yr}^{-1}$ (Song et al., 1989).

\subsection{Sampling methods}

Four adjacent hillslopes (67 sites) were selected to measure soil moisture content. A sampling network was constructed over the four hillslopes, with $20 \mathrm{~m}$ interval to produce a total of 67 sampling sites marked by stakes. The $20-\mathrm{m}$ spatial resolution was chosen to minimize sampling time, so that the results would not be significantly affected by diurnal variations in soil moisture content. Another group of sample sites (14 sites) distributed throughout the entire catchment, was selected to cover the full range of soil moisture conditions in the catchment (Qiu et al., 2001). 
Thus, 81 sites were sampled in total. Among all the sampling sites, 56 sites (70\%) were selected randomly for regression analysis and 25 sites (30\%) were used as validation data to compare and evaluate the regression models.

\subsection{Survey methods}

\subsubsection{Environmental attributes survey}

A land survey of the area was conducted, and the following environmental attributes were recorded at each sampling site: land use type, slope shape, hillslope position, aspect, elevation and slope degree. Rainfall was measured with five automatic raingauges with data-loggers (Eijkelkamp 16.81) located in the catchment. Average rainfall for these five raingauges was $178 \mathrm{~mm}$ during the study period (May-September 1999).

\subsubsection{Soil moisture measurement}

Volumetric soil moisture was measured using a portable Delta$\mathrm{T}$ theta probe (Eijkelkamp Agrisearch Equipment, The Netherlands) at approximately two week intervals from May to September 1999, providing a spectrum of moisture conditions ranging from dry to wet, and covering most of the growing season. Measurements were done at five depths: $0-5 \mathrm{~cm}, 10-15 \mathrm{~cm}$, $20-25 \mathrm{~cm}, 40-45 \mathrm{~cm}$ and $70-75 \mathrm{~cm}$. To measure at these depths, a soil auger was used to drill a hole to the designated depth, after which the theta probe was used to measure moisture content in the bottom of the hole. Five repeat measurements were performed at each depth by drilling 5 holes for each depth within a distance of $1 \mathrm{~m}$. The mean soil moisture content for the five auger-holes was computed to give soil moisture of the sample site. Ten sampling locations were used to measure soil moisture, which resulted in approximately 20,250 measurements of soil moisture over the observation period.

\subsection{Derivation of variables}

\subsubsection{Environmental variables}

Seven types of land use have been identified in field: shrub land, woodland, orchard, intercropping land, wasteland, fallow land, and cropland. The slope shape was classified into four types: convex slope, straight slope, terrace, and concave slope. Hillslope position was divided into five types, i.e. up, middle-up, middle, middledown and down. Aspect (clockwise from north), which is a circular variable, was transformed into cos(aspect), as recommended by Bourennane et al. (1996) and King et al. (1999). Relative elevation was defined as the elevation difference with the catchment outlet. Slope gradient was recorded in degrees. The categorical variables, including land use, slope shape and hillslope position were transformed into "dummy" variables ( 0 for absence and 1 for presence) (Montgomery et al., 2006). As a result, 19 environmental sub-variables are used as predictors for soil moisture content.

\subsubsection{Soil moisture variables}

The time-averaged soil moisture and the layer-averaged soil moisture are the dependent variables in this study. In this study, soil moisture content of plot $i$, layer $j$ and sampling occasion $k$ is expressed as $M_{i, j, k}$. $N_{l}$ represents the number of sampling soil layer or soil depths and is 5 in this study; $N_{t}$ is the number of sampling occasion and is 10 in this study.

1. Mean soil moisture content in $0-75 \mathrm{~cm}$ on plot $i\left(M_{i}\right)$ is given by

$$
M_{i}=\frac{1}{N_{l}} \sum_{j=1}^{N_{l}} M_{i, j}
$$

2. Time-averaged soil moisture content on plot $i$ and in layer $j$ $\left(M_{i, j}\right)$ is given by

$M_{i, j}=\frac{1}{N_{t}} \sum_{k=1}^{N_{t}} M_{i, j, k}$

3. Layer-averaged soil moisture content on plot $i$ and on sampling occasion $k\left(M_{i, k}\right)$ is given as

$M_{i, k}=\frac{1}{N_{l}} \sum_{j=1}^{N_{l}} M_{i, j, k}$

\subsection{Statistical analysis}

The coefficients of correlation $(r)$ were used to determine the correlation among environmental attributes for the 81 sampling sites.

Principal component analysis (PCA) was used to summarize the main gradient in the environmental data of the 81 sampling sites by simple linear transformation, similar to the basic linear regression models, by iteratively computing the vector loading and the component scores (Odeh et al., 1991).

Detrended correspondence analysis (DCA) based on the nonlinearity relationships hypothesis, i.e. the Gauth model, is reported to be more robust in dealing with non-linear relationships (Ter Braak, 1988). DCA was used to average the environmental variables of the 81 sampling sites into ordination values of several ordination axes.

Multiple-linear regressions were performed to develop the spatial prediction models of soil moisture content based on independent variables of 56 sampling sites, including environmental variables or principal axes from PCA or DCA. Using different methods, we can construct a variety of regression models from the same set of variables (Montgomery et al., 2006). Generalized multiple-linear regression models provide a regression analysis for one dependent variable (such as soil moisture) by one or more categorical and/or numerical variables, such as land use, terrain indices and principal axes. In addition, regression models were developed by using the enter-method and by using the stepwisemethod. The stepwise-method is a combination of forward enter and backward elimination procedures (Montgomery et al., 2006). The probability for entry was Pin $=0.01$ and the probability for removal was Pout $=0.05$.

The DCA was performed using CANOCO statistical program (Ter Braak, 1988), while the other analyses (including correlation analysis, PCA, regression) were performed using SPSS software (SPSS for windows 8.0, SPSS Inc.).

\subsection{Indices of model assessment}

No single prediction model can ever be expected to out-perform all other models on all reasonable data sets examined. Therefore, models should satisfy several assessment criteria before they are accepted as satisfactory (Laslett et al., 1987). With this in mind, five classes of measures (total 13 indices) of 25 sampling sites were used to evaluate the models.

\subsubsection{Summary statistics indices}

The comparisons of the mean, the stand deviation $(S D)$, the minimum (Min) and the maximum (Max) between predicted and observed soil moisture content can provide the basic supporting information for assessment of models fitness (Legates and McCabe, 1999; Willmott et al., 1985). 


\subsubsection{Correlation-based indices}

The coefficient of determination $R^{2}$ is the square of the Pearson's product-moment correlation coefficient and describes the proportion of the total variance in the observed data that can be explained by the model (McKenzie et al., 1991). It ranges from 0.0 to 1.0 , with higher values indicating better agreement, and is given by:

$R^{2}=\left\{\frac{\sum_{i=1}^{N}\left(O_{i}-\bar{O}\right)\left(P_{i}-\bar{P}\right)}{\left[\sum_{i=1}^{N}\left(O_{i}-\bar{O}\right)^{2}\right]^{0.5}\left[\sum_{i=1}^{N}\left(P_{i}-\bar{P}\right)^{2}\right]^{0.5}}\right\}^{2}$

where, $O_{i}$ and $P_{i}$ are the observed and predicted soil moisture on plot i respectively, $\bar{O}$ and $\bar{P}$ are the mean soil moisture observed and predicted respectively, $N$ is the number of plots.

$R^{2}$ is limited in that its value increases with the increasing of number of independent variables $(N v)$. So, it is adjusted as:

$R_{a}^{2}=R^{2}-\frac{N v\left(1-R^{2}\right)}{N-N v-1}$

These two indices measure the optimums of models in predicting soil moisture content and they should be close to 1 for the most optimum prediction methods. However, they are insensitive to additive and proportional differences between the model predictions and observations. Large values of these indices can be obtained even when the model-predicted values differ considerably in magnitude and variability (Legates and McCabe, 1999). So, they cannot measure the precision of models.

\subsubsection{Absolute error indices}

These measures, which are non-negative statistics that have no upper bound, describe the difference between the model predictions and observations in the units of the variable (Willmott, 1981).

The mean absolute error (MAE) is given by

$M A E=N^{-1} \sum_{i=1}^{N}\left|O_{i}-P_{i}\right|$

The square root of the mean square error (RMSE) is given by

$R M S E=\sqrt{N^{-1} \sum_{i=1}^{N}\left(O_{i}-P_{i}\right)^{2}}$

These two indices measure the bias or precision of prediction and they should be as small as possible for unbiased and precise prediction models (Odeh et al., 1994).

In general, $R M S E \geq M A E$ for the range of most values. Thus, the degree to which RMSE exceeds MAE is an indicator of the extent to which outliers (or variance in the differences between the modeled and observed values) exist in the data (Legates and McCabe, 1999). The outlier is given by

Outlier $=$ RMSE - MAE

Of course, the higher values indicate more evident outliers in prediction.

\subsubsection{Relative-error indices}

The relative-error indices, which are dimensionless measures, can provide a relative assessment of model performance (Legates and McCabe, 1999). This is useful in comparing the models for predicting soil attributes with different units.
The coefficient of efficiency which ranges from minus infinity to 1.0 , with higher values indicating better agreement, was defined as (Nash and Sutcliffe, 1970):

$E=1.0-\frac{\sum_{i=1}^{N}\left(O_{i}-P_{i}\right)^{2}}{\sum_{i=1}^{N}\left(O_{i}-\bar{O}\right)^{2}}$

A value of zero for $E$ indicates that the observed mean $\bar{O}$ is as good a predictor as the model, while negative values indicate that the observed mean is a better predictor than the model (Wilcox et al., 1990).

The index of agreement d, is given by (Willmott, 1981):

$d=1.0-\frac{\sum_{i=1}^{N}\left(O_{i}-P_{i}\right)^{2}}{\sum_{i=1}^{N}\left(\left|P_{i}-\bar{O}\right|+\left|O_{i}-\bar{O}\right|\right)^{2}}$

Which varies from 0.0 to 1.0 , with higher values indicating better agreement between the model and observations.

These two indices represent an improvement over $R^{2}$ and $R_{a}^{2}$ for model evaluation purposes in that they are sensitive to differences in the observed and model-predicted means and variances but also are sensitive to extreme values just like $R^{2}$ and $R_{a}^{2}$ (Legates and McCabe, 1999).

\subsubsection{Information criteria}

Only comparison of goodness of fit and precision of models is not enough for selecting satisfactory models, because increasing the number of predictor variables almost always improves the apparent fit of the regression (Lark, 1999). In addition, increasing the number of predictors causes increasing cost in survey and analysis (Odeh et al., 1994). Appropriate statistics for comparing regressions of the same observations of soil moisture content on different sets of independent variables are the Akaike information criterion (AIC) and Schwarz or Bayesian information criterion (SIC) (Webster and McBratney, 1989), since these two criteria can provide a satisfactory compromise between goodness of fit and parsimony.

The $A I C$ is estimated by

$A I C=N \ln (S S E)+2 N e$

Where, Ne is the number of environmental variables evolved, SSE is the sum of square of error, and is given by

$S S E=\sum_{i=1}^{N}\left(O_{i}-P_{i}\right)^{2}$

The SIC is defined by

$S I C=N \ln (S S E)+N e \ln (N)$

The difference between $A I C$ and SIC is in the second term on the right-hand side: thus if $N \geq 8$ then the SIC will tend to favor models with fewer parameters than those chosen by the AIC.

When comparing two models with different numbers of predictors, the model to select should be the one with lowest values of $A I C$ or SIC. Note that, in this paper, $\mathrm{Ne}$ is the number of environmental variables involved rather than the number of parameters (Webster and McBratney, 1989) or the number of independent variables (Lark, 1999). For example, for PCA-EMLRMs (multiple-linear regression models with PCA axes on environmental attributes using the enter-method, in which all the first four axes are introduced into the models), the number of independent variables (i.e. the number of axes) is 4 . However, Ne is designated as 19 rather than 4 because all the 19 environmental variables are used in PCA. 
Table 1

Generalized multiple-linear regression models with environmental attributes (GMLRMs) developed to predict time-averaged soil moisture content.

\begin{tabular}{|c|c|c|c|c|c|c|}
\hline \multirow[t]{2}{*}{ Independent variables } & \multicolumn{2}{|c|}{ Dependent variables } & \multirow{2}{*}{$\frac{\text { Time-averaged }}{20-25 \mathrm{~cm}^{\mathrm{b}}}$} & \multirow{2}{*}{$\frac{\text { Soil moisture }}{40-45 \mathrm{~cm}^{\mathrm{b}}}$} & \multirow{2}{*}{$\frac{\text { Content }\left(M_{j}\right)}{70-75 \mathrm{~cm}^{\mathrm{b}}}$} & \multirow{2}{*}{$\frac{\% \mathrm{v} / \mathrm{v}}{0-75 \mathrm{~cm}^{\mathrm{c}}}$} \\
\hline & $0-5 \mathrm{~cm}^{\mathrm{b}}$ & $10-15 \mathrm{~cm}^{\mathrm{b}}$ & & & & \\
\hline Intercept & 11.6390 & 13.2365 & 15.8773 & 19.0825 & 24.7058 & 16.9139 \\
\hline Shrub land ${ }^{\mathrm{a}}$ & 0.6025 & -1.1883 & -2.5570 & -5.1073 & -6.1472 & -2.8842 \\
\hline Woodland ${ }^{\mathrm{a}}$ & 2.1463 & 0.5993 & -1.0307 & -3.3573 & -5.9054 & -1.5129 \\
\hline Orchard $^{\mathrm{a}}$ & -2.0641 & -2.0204 & -3.8541 & -6.0219 & -10.1750 & -4.8314 \\
\hline Intercropping land ${ }^{\mathrm{a}}$ & 0.0324 & -0.4001 & -1.0632 & -1.9849 & -2.5353 & -1.1904 \\
\hline Wasteland $^{\mathrm{a}}$ & -1.3443 & -0.6323 & -2.3025 & -3.4509 & -7.9844 & -3.1504 \\
\hline Fallow land ${ }^{\mathrm{a}}$ & -0.1296 & 0.1089 & -0.1290 & -0.8185 & -1.2166 & -0.4344 \\
\hline Cropland $^{\mathrm{a}}$ & 0.0000 & 0.0000 & 0.0000 & 0.0000 & 0.0000 & 0.0000 \\
\hline Convex slope $\mathrm{e}^{\mathrm{a}}$ & 0.1136 & 0.9742 & 1.2337 & 0.4742 & -0.4841 & 0.4650 \\
\hline Straight slope ${ }^{a}$ & -0.4171 & -0.7322 & -1.1012 & -1.2550 & -1.5263 & -1.0070 \\
\hline Terrace $^{\mathrm{a}}$ & -0.6652 & -0.5908 & -0.6182 & -0.8376 & -1.1192 & -0.7668 \\
\hline Concave slope $^{a}$ & 0.0000 & 0.0000 & 0.0000 & 0.0000 & 0.0000 & 0.0000 \\
\hline$U P^{a}$ & 0.1149 & -1.1484 & -1.6399 & -2.4276 & -3.3576 & -1.6907 \\
\hline Middle-up ${ }^{a}$ & -0.5207 & -2.2636 & -3.0812 & -4.1388 & -5.5181 & -3.1050 \\
\hline Middle $^{\mathrm{a}}$ & -0.4625 & -1.5909 & -2.0436 & -3.1392 & -4.4108 & -2.3290 \\
\hline Middle-down $^{\mathrm{a}}$ & -0.7967 & -1.8816 & -2.2059 & -2.9389 & -4.1349 & -2.3932 \\
\hline Down $^{a}$ & 0.0000 & 0.0000 & 0.0000 & 0.0000 & 0.0000 & 0.0000 \\
\hline Cos(aspect) & -0.0671 & 0.0386 & 0.1359 & 0.3032 & 0.1065 & 0.1043 \\
\hline Relative elevation & -0.0276 & -0.0153 & -0.0194 & -0.0199 & -0.0419 & -0.0249 \\
\hline Slope gradient & -0.0549 & -0.0512 & -0.0460 & -0.0608 & -0.0463 & -0.0517 \\
\hline
\end{tabular}

${ }^{a}$ Binary response ( 0 for absence and 1 for presence).

${ }^{\mathrm{b}}$ and ${ }^{\mathrm{c}}$ From Eq.(2) and Eq.(1) respectively.

\section{Results}

\subsection{Analysis of environmental attributes}

\subsubsection{Correlation analysis}

The correlation among each pair of environmental variables is given in Appendix 2 (electronic version). All the qualitative variables are transformed into binary data or dummy variables (Montgomery et al., 2006). Clearly, there is significant correlation among environmental attributes. Land use is significantly correlated to all other five environmental attributes. Slope shape shows a significant correlation with slope gradient, while hillslope position is significantly correlated with relative elevation. All of these interrelations in environmental variables may have significant influence on regression models for spatial prediction of soil moisture content.

\subsubsection{Principle component analysis (PCA)}

In this and in the following section, all the environmental factors are summarized or averaged into the first four ordination axes values using PCA and DCA respectively. The first four axis values resulting from PCA are given in Appendix 3 (electronic version). Clearly, PCA is satisfactory in summarizing the main gradient in environmental variable data since the sum (0.9989) of eigenvalue of the first four axes of PCA is close to 1.0 (Wotling et al., 2000). This indicates significance in linear correlation among environmental variables because PCA uses a linear transformation to convert environmental variables into principal components (i.e. axes) (Parinet et al., 2004; Camdevyren et al., 2005). In addition, analysis of correlation indicated little correlation between each of the first four axes of PCA, i.e. each axis represents specific aspects of environmental attributes at different scales.

Clearly, the hillslope-scale attributes (relative elevation and hillslope position) contribute to axis 1 , and axis 2 indicates the gradients dominated by site-scale attributes (slope gradient and slope shape). Axis 3 represents the controlling of catchment-scale attributes (land use and aspect), while axis 4 shows the influence of multiple-scale attributes. This shows the success of PCA in summarizing the environmental attributes involved in this study, i.e. PCA can provide good estimations of the role of each environmental attribute. Of course, such small correlation among the first four axes makes the axes good explanatory variables in prediction of soil moisture.

\subsubsection{Detrended correspondence analysis (DCA)}

The first axes values of environmental attribute resulting from DCA are given in Appendix 4 (electronic version). The sum (0.0754) of eigenvalues of the first four axes of DCA is very small. This indicates insignificance in non-linear relationships among environmental variables because DCA performs a non-linear transformation of environmental variables into the axes (Qiu and Zhang, 1999; Ter Braak, 1988). Axis 1 is controlled by land use and slope shape, axis 2 represents the hillslope position and land use, axis 3 mainly represents slope shape and land use and axis 4 indicates the hillslope position and land use. Analysis of correlation indicates that axis 3 and axis 4 show significant correlation with axis 1 and axis 2. Such interaction among the first four axes of DCA can be attributed to overestimates of the roles of some key factors such as hillslope position and land use.

\subsection{Spatial prediction models of soil moisture}

\subsubsection{General multiple-linear regression models (GMLRMs)}

The prediction models of time-averaged soil moisture content at six soil depths and of layer-averaged soil moisture on 10 observations are developed using GMLRMs as shown in Table 1 and Table 2 respectively. One sub-variable of each categorical attributes is designated as zero for its regression coefficients during regression, such as cropland, concave slope and down (Montgomery et al., 2006). For the same categorical attributes, the regression coefficients of other sub-variables can reflect its relative values in soil moisture prediction based on a comparison with the deleted subvariables (regression coefficients $=0$ ) (Montgomery et al., 2006). For example, the regression coefficients of shrub land are very low for prediction of time-averaged soil moisture content in soil layers of $10-75 \mathrm{~cm}$, while it is not so low at depth $0-5 \mathrm{~cm}$ (Table 1 ). This is because, at larger depth, the shrub land is generally drier than cropland because of the strong transpiration of dense shrub, while at the surface this is not so obvious because of the weak evaporation of a surface covered by dense shrub (Qiu et al., 2001). 
Table 2

Generalized multiple-linear regression models with environmental attributes (GMLRMs) developed to predict layer-averaged soil moisture content.

\begin{tabular}{|c|c|c|c|c|c|c|c|c|c|c|}
\hline \multirow[t]{2}{*}{ Independent Variables } & \multicolumn{2}{|c|}{ Dependent variables } & \multicolumn{3}{|c|}{ Layer-averaged soil } & \multicolumn{2}{|c|}{ Moisture content } & \multirow{2}{*}{$\frac{\left(M_{i, k}\right)^{\mathrm{b}}}{2-\text { Aug }}$} & \multicolumn{2}{|l|}{$\% \mathrm{v} / \mathrm{v}$} \\
\hline & 2-May & 13-May & 23-May & 10-Jun & 23-Jun & 12-Jul & 18-Jul & & 10-Aug & 9-Sep \\
\hline Intercept & 22.4579 & 18.8626 & 20.2843 & 12.2659 & 17.5872 & 22.1563 & 15.0683 & 11.5941 & 15.2884 & 8.7463 \\
\hline Shrub land ${ }^{\mathrm{a}}$ & -0.1329 & -2.0036 & -1.7852 & -0.9208 & -0.7426 & -3.8505 & -5.4318 & -6.7165 & -4.8657 & -2.5463 \\
\hline Woodland ${ }^{\mathrm{a}}$ & -0.6313 & -5.2922 & -2.6647 & 0.3395 & -0.7346 & -2.4017 & -0.8589 & -0.9462 & -1.7310 & 0.0862 \\
\hline Orchard $^{\mathrm{a}}$ & -7.4656 & -8.1998 & -6.7058 & -4.3483 & -5.8888 & -3.5565 & 0.0960 & -1.4598 & -7.3419 & -1.3494 \\
\hline Intercropping land ${ }^{\mathrm{a}}$ & -1.2947 & -3.5466 & -2.7579 & -2.0193 & -1.3680 & -0.7445 & -1.5622 & 0.3004 & 1.1041 & -0.1304 \\
\hline Wasteland $^{\mathrm{a}}$ & -5.8278 & -4.0386 & -3.8336 & 2.4094 & -4.5587 & -5.5621 & -0.8205 & 1.3370 & -7.5073 & -0.5711 \\
\hline Fallow land ${ }^{\mathrm{a}}$ & 1.5561 & -2.0458 & 0.3950 & 0.7359 & 1.0397 & -2.4361 & -1.3208 & -2.4466 & -0.6154 & 0.4392 \\
\hline Cropland $^{\mathrm{a}}$ & 0.0000 & 0.0000 & 0.0000 & 0.0000 & 0.0000 & 0.0000 & 0.0000 & 0.0000 & 0.0000 & 0.0000 \\
\hline Convex slope $^{a}$ & 2.4255 & 5.0974 & 2.9289 & 0.3793 & -1.2132 & -1.1279 & -1.7376 & -0.6140 & -1.2504 & 0.1486 \\
\hline Straight slope $\mathrm{a}^{\mathrm{a}}$ & -2.1595 & -0.8228 & -0.6676 & -1.1859 & -1.5367 & 0.1940 & -1.4677 & -0.7789 & -1.0155 & -0.4403 \\
\hline Terrace $^{\mathrm{a}}$ & -1.2529 & -1.9494 & -1.6139 & -0.8930 & -0.4730 & 0.0288 & -0.4316 & -0.9196 & -0.1487 & -0.4104 \\
\hline Concave slope ${ }^{a}$ & 0.0000 & 0.0000 & 0.0000 & 0.0000 & 0.0000 & 0.0000 & 0.0000 & 0.0000 & 0.0000 & 0.0000 \\
\hline$U^{a}$ & -1.0466 & -8.7352 & -5.1979 & -2.2700 & -0.0223 & 0.1649 & -1.2607 & -0.7001 & 0.5621 & -1.7187 \\
\hline Middle-up $^{a}$ & -3.4048 & -10.7135 & -7.3014 & -3.6816 & -1.3869 & -0.6237 & -1.7422 & -1.7668 & -0.5651 & -2.0232 \\
\hline Middle $^{a}$ & -1.7876 & -8.8263 & -5.8270 & -2.3627 & -1.1196 & -1.4718 & -0.9745 & -0.8309 & -0.2069 & -1.3157 \\
\hline Middle-down ${ }^{a}$ & -2.6335 & -7.7598 & -5.3069 & -2.2933 & -0.9323 & -1.3711 & -1.8376 & -1.0009 & 0.1169 & -1.5017 \\
\hline Down $^{a}$ & 0.0000 & 0.0000 & 0.0000 & 0.0000 & 0.0000 & 0.0000 & 0.0000 & 0.0000 & 0.0000 & 0.0000 \\
\hline Cos(aspect) & 0.1710 & 0.9708 & 0.8143 & -0.5771 & -0.3724 & -0.0839 & 0.6668 & 0.2648 & -0.4529 & -0.1138 \\
\hline Relative elevation & -0.0567 & 0.0031 & -0.0191 & -0.0094 & -0.0542 & -0.0339 & -0.0010 & 0.0096 & -0.0290 & -0.0059 \\
\hline Slope gradient & -0.1037 & -0.1675 & -0.1593 & -0.0936 & -0.0444 & -0.0365 & 0.0279 & -0.0274 & 0.0466 & -0.0071 \\
\hline
\end{tabular}

${ }^{a}$ Binary response ( 0 for absence and 1 for presence).

${ }^{\mathrm{b}}$ From Eq (3).

In addition, all the model parameters for prediction of layeraveraged soil moisture content show differences for different observation occasions (Table 2), because of the significant seasonal dynamics of soil moisture content (Qiu et al., 2001). For example, the regression coefficients of shrub land change significantly and are especially low during July and August (Table 2), because soil moisture content also changes significantly for shrub land and it is especially low in July and August due to strong transpiration in summer (Qiu et al., 2001).

\subsubsection{Stepwise multiple-linear regression models (SMLRMs)}

The prediction models of time-averaged soil moisture at six soil depths and of layer-averaged soil moisture on ten observations as developed using SMLRMs are shown in Table 3 and Table 4 respectively. The relationships between environmental attributes and soil moisture content indicated by both the analyses of correlation and variance (Qiu et al., 2001) are also obvious in the stepwise regressions (Table 3 and Table 4). In addition, the reciprocal relations among environmental attributes (Appendix 2, electronic version) can also considerably influence the stepwise regression. For example, land use is selected by all regression equations for predicting all aspects of soil moisture because of the significant relations between land use and soil moisture content (Qiu et al., 2001). On the other hand, slope shape and cos(aspect) are not entered into any regression models because of their weak relationships with soil moisture content (Qiu et al., 2001). Most regression models exclude relative elevation though it influences soil moisture significantly (Qiu et al., 2001). This may be explained

Table 3

Multiple-linear stepwise regression models with environmental attributes using stepwise-method (SMLRMs) developed to predict time-averaged soil moisture content.

\begin{tabular}{|c|c|c|c|c|c|c|}
\hline \multirow[t]{2}{*}{ Independent Variables } & \multicolumn{2}{|c|}{ Dependent variables } & \multirow{2}{*}{$\frac{\text { Time-averaged }}{20-25 \mathrm{~cm}^{\mathrm{b}}}$} & \multirow{2}{*}{$\frac{\text { Soil moisture }}{40-45 \mathrm{~cm}^{\mathrm{b}}}$} & \multirow{2}{*}{$\frac{\text { Content }\left(M_{j}\right)}{70-75 \mathrm{~cm}^{\mathrm{b}}}$} & \multirow{2}{*}{$\frac{\% \mathrm{v} / \mathrm{v}}{0-75 \mathrm{~cm}^{\mathrm{c}}}$} \\
\hline & $0-5 \mathrm{~cm}^{\mathrm{b}}$ & $10-15 \mathrm{~cm}^{\mathrm{b}}$ & & & & \\
\hline Intercept & 9.0271 & 9.0073 & 10.4556 & 11.2752 & 12.2186 & 9.9673 \\
\hline Shrub land ${ }^{\mathrm{a}}$ & - & -1.3012 & -2.4541 & -3.2557 & -3.6390 & -2.1752 \\
\hline Woodland ${ }^{\mathrm{a}}$ & 3.1014 & 1.1299 & - & - & - & - \\
\hline Orchard $^{\mathrm{a}}$ & - & - & -2.2736 & -2.5889 & -3.7648 & -2.4556 \\
\hline Intercroppingland $^{\mathrm{a}}$ & - & - & - & - & - & - \\
\hline Wasteland ${ }^{\mathrm{a}}$ & - & - & - & - & - & - \\
\hline Fallow land ${ }^{\mathrm{a}}$ & - & - & - & - & - & - \\
\hline Cropland $^{\mathrm{a}}$ & - & - & - & 1.5290 & 2.7830 & 0.8274 \\
\hline Convex slope $^{\mathrm{a}}$ & - & - & - & - & - & - \\
\hline Straight slope ${ }^{a}$ & - & - & - & - & - & - \\
\hline Terrace $^{\mathrm{a}}$ & - & - & - & - & - & - \\
\hline Concave slope $^{\mathrm{a}}$ & - & - & - & - & - & - \\
\hline $\mathrm{UP}^{\mathrm{a}}$ & - & - & - & - & - & - \\
\hline Middle-up ${ }^{a}$ & - & - & - & - & -1.6020 & - \\
\hline Middle $^{\mathrm{a}}$ & - & - & - & - & - & - \\
\hline Middle-down $^{\mathrm{a}}$ & - & - & - & - & - & - \\
\hline Down $^{\mathrm{a}}$ & - & 1.9463 & 2.4943 & 3.1028 & 4.0465 & 2.9172 \\
\hline Cos(aspect) & - & - & - & - & - & - \\
\hline Relative elevation & -0.0136 & - & - & - & - & - \\
\hline Slope gradient & -0.0511 & -0.0597 & -0.0732 & -0.0973 & -0.1260 & -0.0802 \\
\hline
\end{tabular}

- Independent variables not entered in the stepwise regression.

${ }^{a}$ Binary response ( 0 for absence and 1 for presence).

${ }^{b}$ and ${ }^{\mathrm{c}}$ From Eq.(2) and Eq.(1) respectively. 
Table 4

Multiple-linear stepwise regression models with environmental attributes using stepwise-method (SMLRMs) developed to predict layer-averaged soil moisture content.

\begin{tabular}{|c|c|c|c|c|c|c|c|c|c|c|}
\hline \multirow[t]{2}{*}{ Independent Variables } & \multicolumn{2}{|c|}{ Dependent variables } & \multicolumn{3}{|c|}{ Layer-averaged soil } & \multicolumn{2}{|c|}{ Moisture content } & \multirow{2}{*}{$\frac{\left(M_{i, k}\right)^{\mathrm{b}}}{2-A u g}$} & \multicolumn{2}{|l|}{$\% \mathrm{v} / \mathrm{v}$} \\
\hline & 2-May & 13-May & 23-May & 10-Jun & 23-Jun & 12-Jul & 18-Jul & & 10-Aug & 9-Sep \\
\hline Intercept & 12.0854 & 6.9795 & 9.5120 & 7.2282 & 12.4118 & 13.4815 & 12.5845 & 10.8775 & 11.3759 & 5.9200 \\
\hline Shrub land ${ }^{\mathrm{a}}$ & - & - & - & -2.0012 & - & -1.9931 & -4.5528 & -6.3691 & -5.5592 & -3.2250 \\
\hline Woodland ${ }^{\mathrm{a}}$ & - & - & - & - & - & - & - & - & - & - \\
\hline Orchard $^{\mathrm{a}}$ & -4.2508 & -4.2312 & -3.4621 & -4.4036 & -3.5572 & - & - & - & -4.9609 & - \\
\hline Intercropping land ${ }^{\mathrm{a}}$ & - & - & - & -1.8073 & -1.4414 & 1.9885 & - & - & - & - \\
\hline Wasteland $^{\mathrm{a}}$ & - & - & - & - & - & - & - & - & -4.3559 & - \\
\hline Fallow land ${ }^{\mathrm{a}}$ & - & - & 2.1422 & - & - & - & - & - & - & - \\
\hline Cropland $^{\mathrm{a}}$ & - & 2.4695 & 2.0142 & - & - & 2.8984 & - & - & - & - \\
\hline Convex slope $^{\mathrm{a}}$ & - & - & - & - & - & - & - & - & - & - \\
\hline Straight slope $\mathrm{a}^{\mathrm{a}}$ & - & - & - & - & - & - & - & - & - & - \\
\hline Terrace $^{a}$ & - & - & - & - & - & - & - & - & - & - \\
\hline Concave slope $^{a}$ & - & - & - & - & - & - & - & - & - & - \\
\hline $\mathrm{UP}^{\mathrm{a}}$ & - & - & - & - & - & - & - & - & - & - \\
\hline Middle-up ${ }^{a}$ & - & - & -1.3578 & - & - & - & - & - & - & - \\
\hline Middle $^{\mathrm{a}}$ & - & - & - & - & - & - & - & - & - & - \\
\hline Middle-down ${ }^{a}$ & - & - & - & - & - & - & - & - & - & - \\
\hline Down $^{a}$ & 3.9241 & 7.2571 & 5.8282 & 3.4709 & 1.6664 & 2.0608 & 1.3649 & - & - & 1.6765 \\
\hline Cos(aspect) & - & - & - & - & - & - & - & - & - & - \\
\hline Relative elevation & - & - & - & - & -0.0228 & - & - & - & - & - \\
\hline Slope gradient & -0.1907 & -0.1479 & -0.1601 & -0.0745 & -0.1284 & - & - & - & - & - \\
\hline
\end{tabular}

- Independent variables not entered in the stepwise regression.

a Binary response ( 0 for absence and 1 for presence).

${ }^{\mathrm{b}}$ From Eq (3).

by the fact that relative elevation shows significant association with other environmental factors, especially with hillslope position (Appendix 2, electronic version).

\subsubsection{Multiple-linear regression models based on PCA (PCA-EMLRMs)}

The prediction models of soil moisture are developed using PCAEMLRMs (Table 5). All the first four axes were introduced into models regardless of their significance. Axis 1 representing hillslope-scale attributes and axis 2 representing site-scale attributes can exhibit stronger influence on soil moisture than axis 3 representing catchment-scale attributes and axis 4 representing multiple-scale attributes based on the comparison of magnitude of regression coefficients. This is consistent with conclusion from analyses of correlation and variance (Qiu et al., 2001). The positive regression coefficients of axis 1 show that it is wetter on the lower parts of the hillslope than on the higher parts (Qiu et al., 2001). However, the negative coefficients of axis 2 confirm the conclusion from correlation analysis, i.e. that plots on steeper slopes are drier than those on gentler slopes (Qiu et al., 2001).

\subsubsection{Stepwise multiple-linear regression models based on PCA (PCA-SMLRMs)}

The prediction models of soil moisture are developed using PCASMLRMs (Table 6). The selection of axis representing environmental attributes at different scales is determined by the relationships of soil moisture content with environmental attributes. It is clear that axis 1 (representing hillslope-scale attributes) and axis 2 (representing site-scale attributes such as slope gradient) are selected by the stepwise regression because of the strong influence of these attributes on soil moisture (Qiu et al., 2001). However, axis 3 (representing catchment-scale attributes such as land use and cos(aspect)) and axis 4 (representing multiple-scale attributes) are selected only by some regression equations. This is almost consistent with results from analyses of correlation and variance (Qiu et al., 2001).

Table 5

Multiple-linear regression models with PCA axes on environmental attributes using enter-method (PCA-EMLRMs) developed to predict soil moisture content.

\begin{tabular}{|c|c|c|c|c|c|c|}
\hline \multirow{2}{*}{$\frac{\text { Dependent variables }}{\text { Soil moisture content }}$} & \multirow[t]{2}{*}{$\% \mathrm{v} / \mathrm{v}$} & \multicolumn{5}{|c|}{ Independent variables } \\
\hline & & Intercept & PCA axis1 & PCA axis2 & PCA axis3 & PCA axis 4 \\
\hline \multirow[t]{6}{*}{ Time-averaged $\left(M_{i, j}\right)$} & $0-5 \mathrm{~cm}^{\mathrm{a}}$ & 6.7544 & 0.6741 & -0.3796 & 0.2959 & 0.3477 \\
\hline & $10-15 \mathrm{~cm}^{\mathrm{a}}$ & 8.5325 & 0.8452 & -0.5002 & 0.2225 & 0.4434 \\
\hline & $20-25 \mathrm{~cm}^{\mathrm{a}}$ & 9.6742 & 0.9903 & -0.7763 & -0.042 & 0.3666 \\
\hline & $40-45 \mathrm{~cm}^{\mathrm{a}}$ & 11.1454 & 1.2478 & -1.1704 & -0.4777 & 0.2984 \\
\hline & $70-75 \mathrm{~cm}^{\mathrm{a}}$ & 12.3883 & 1.6193 & -1.4195 & -0.9414 & 0.322 \\
\hline & $0-75 \mathrm{~cm}^{\mathrm{b}}$ & 9.699 & 1.0757 & -0.8495 & -0.1888 & 0.3554 \\
\hline \multirow[t]{10}{*}{ Layer-averaged $^{\mathrm{c}}\left(M_{i, k}\right)$} & 2-May & 10.0233 & 1.1598 & -1.4353 & 0.3347 & 0.5541 \\
\hline & 13-May & 7.7657 & 1.8358 & -1.0713 & -0.1205 & 0.4345 \\
\hline & 23-May & 9.4954 & 1.5856 & -1.1983 & 0.0088 & 0.498 \\
\hline & 10-Jun & 6.3669 & 1.181 & -0.5389 & -0.1268 & 0.8576 \\
\hline & 23-Jun & 7.6548 & 1.0892 & -0.9142 & -0.1672 & 0.5833 \\
\hline & 12-Jul & 15.8255 & 0.7844 & -0.7997 & -0.7276 & 0.0418 \\
\hline & 18-Jul & 12.5337 & 0.9446 & -0.4844 & -0.0453 & 0.0794 \\
\hline & 2-Aug & 10.4057 & 0.8173 & -0.8319 & -0.2802 & -0.0221 \\
\hline & 10-Aug & 10.7341 & 0.3458 & -1.0466 & -0.6063 & 0.0973 \\
\hline & 9-Sep & 6.033 & 0.8952 & -0.3614 & -0.0752 & 0.3437 \\
\hline
\end{tabular}

a, b and ${ }^{\mathrm{c}}$ From Eq.(2), Eq.(1) and Eq (3) respectively. 
Table 6

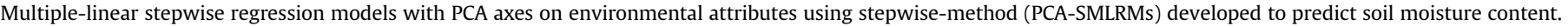

\begin{tabular}{|c|c|c|c|c|c|c|}
\hline \multirow{2}{*}{$\frac{\text { Dependent variables }}{\text { Soil moisture content }}$} & \multirow[t]{2}{*}{$\% \mathrm{v} / \mathrm{v}$} & \multicolumn{5}{|c|}{ Independent variables } \\
\hline & & Intercept & PCA axis1 & PCA axis2 & PCA axis3 & PCA axis 4 \\
\hline \multirow[t]{6}{*}{ Time-averaged $\left(M_{i, j}\right)$} & $0-5 \mathrm{~cm}^{\mathrm{a}}$ & 6.7544 & 0.6741 & -0.3796 & 0.2959 & 0.3477 \\
\hline & $10-15 \mathrm{~cm}^{\mathrm{a}}$ & 8.5325 & 0.8452 & -0.5002 & - & 0.4435 \\
\hline & $20-25 \mathrm{~cm}^{\mathrm{a}}$ & 9.6742 & 0.9903 & -0.7763 & - & 0.3666 \\
\hline & $40-45 \mathrm{~cm}^{\mathrm{a}}$ & 11.1454 & 1.2478 & -1.1704 & -0.4776 & - \\
\hline & $70-75 \mathrm{~cm}^{\mathrm{a}}$ & 12.3883 & 1.6192 & -1.4195 & -0.9413 & - \\
\hline & $0-75 \mathrm{~cm}^{\mathrm{b}}$ & 9.699 & 1.0757 & -0.8495 & - & 0.3553 \\
\hline \multirow[t]{10}{*}{ Layer-averaged $^{\mathrm{c}}\left(M_{i, k}\right)$} & 2-May & 10.0233 & 1.1597 & -1.4352 & - & - \\
\hline & 13-May & 7.7657 & 1.8357 & -1.0713 & - & - \\
\hline & 23-May & 9.4954 & 1.5856 & -1.1983 & - & - \\
\hline & 10-Jun & 6.3669 & 1.181 & -0.5389 & - & 0.8576 \\
\hline & 23-Jun & 7.6548 & 1.0892 & -0.9142 & - & 0.5833 \\
\hline & 12-Jul & 15.8255 & 0.7844 & -0.7997 & -0.7276 & - \\
\hline & 18-Jul & 12.5337 & 0.9446 & -0.4844 & - & - \\
\hline & 2-Aug & 10.4057 & 0.8173 & -0.8319 & - & - \\
\hline & 10-Aug & 10.7341 & - & -1.0466 & -0.6063 & - \\
\hline & 9-Sep & 6.033 & 0.8952 & -0.3614 & - & 0.3437 \\
\hline
\end{tabular}

- Independent variables not entered in the stepwise regression.

a, b and ${ }^{c}$ From Eq.(2), Eq.(1) and Eq (3) respectively.

\subsubsection{Multiple-linear regression models based on DCA (DCA-EMLRMs)}

The prediction models of soil moisture are developed using DCA-EMLRMs (Table 7). Axis 2 and axis 3 appear to be more strongly related with soil moisture than the other two axes based on a comparison of magnitude of regression coefficients.

\subsubsection{Stepwise multiple-linear regression models based on DCA (DCA-SMLRMs)}

The stepwise regression equations of soil moisture with the first four axes of DCA are shown in Table 8. The entering and removing of axes is dependent on both the relationship between axes and soil moisture content and the reciprocal correlation among axes. It should be noted that none of the first four axes can be selected by stepwise regression to predict the layer-averaged soil moisture on 2 August 1999.

\subsection{Assessment of prediction models}

A measure of the performance of the multi-linear regression equations is the comparison of summary statistics between predicted and measured soil moisture (Fig. 1). Obviously, there is little difference between observed and predicted mean for five of the methods. The only exception is the DCA-SMLRMs in predicting mean soil moisture at $0-75 \mathrm{~cm}$ (Fig. 1a). Based on the degree to which the predicted standard deviation (SD) matches the observed (Fig. 1b), the following sequence is obvious, i.e. GMLRMs $>$ SMLRMs $>$ PCAEMLRMs $>$ PCA-SMLRMs $>$ DCA-EMLRMs $>$ DCA-SMLRMs. Such a trend is also observed in the goodness of fit of predicted minimum with the observed minimum soil moisture content. Maximum soil moisture content shows a similar sequence too, but with the DCAbased models performing better than the PCA-based models.

The coefficient of determination $\left(R^{2}\right)$ describes the proportion of the total variance in the observed data that can be explained by the model, and can measure the degree of optimum of models. Clearly, in this study, land use and topography together explain as much as $75 \%$ of the soil moisture variability (Fig. 2a). There is great difference in $R^{2}$ among different methods, and the following sequence is generated from these analyses: with-attribute group models $>$ PCA-based group models $>$ DCA-based group models. Within each group models, the enter-method models are generally better than the stepwise-method models, but such within-group

Table 7

Multiple-linear regression models with DCA axes on environmental attributes using enter-method (DCA-EMLRMs) developed to predict soil moisture content.

\begin{tabular}{|c|c|c|c|c|c|c|}
\hline \multirow{2}{*}{$\frac{\text { Dependent variables }}{\text { Soil moisture content }}$} & \multirow[t]{2}{*}{$\% \mathrm{v} / \mathrm{v}$} & \multicolumn{5}{|c|}{ Independent variables } \\
\hline & & Intercept & DCA axis1 & DCA axis2 & DCA axis3 & DCA axis4 \\
\hline \multirow[t]{6}{*}{ Time-averaged $\left(M_{i, j}\right)$} & $0-5 \mathrm{~cm}^{\mathrm{a}}$ & 5.42 & 2.3 & 17.57 & -7.22 & 2.18 \\
\hline & $10-15 \mathrm{~cm}^{\mathrm{a}}$ & 7.76 & 3.76 & 18.4 & -18.38 & 4.23 \\
\hline & $20-25 \mathrm{~cm}^{\mathrm{a}}$ & 10.57 & 2.18 & 14.57 & -28.34 & 1.74 \\
\hline & $40-45 \mathrm{~cm}^{\mathrm{a}}$ & 14.73 & 0.91 & 9.42 & -44.62 & -6.88 \\
\hline & $70-75 \mathrm{~cm}^{\mathrm{a}}$ & 18.33 & 1.19 & 5.5 & -64.05 & -11.8 \\
\hline & $0-75 \mathrm{~cm}^{\mathrm{b}}$ & 11.36 & 2.07 & 13.09 & -32.53 & -2.1 \\
\hline \multirow[t]{10}{*}{ Layer-averaged $^{\mathrm{c}}\left(M_{i, k}\right)$} & 2-May & 10.67 & -0.43 & 27.34 & -37.52 & 9.79 \\
\hline & 13-May & 11.5 & 8.24 & 24.72 & -70.38 & -12.9 \\
\hline & 23-May & 12.56 & 6.39 & 25.82 & -66.05 & -4.75 \\
\hline & 10-Jun & 7.47 & 8.62 & 21.1 & -47.28 & -1.01 \\
\hline & 23-Jun & 10.07 & 2.22 & 13.54 & -41.01 & -2.83 \\
\hline & 12-Jul & 19.46 & -2.78 & -2.29 & -21.05 & -16.17 \\
\hline & 18-Jul & 12.51 & 3.47 & 13.51 & -15.84 & -4.23 \\
\hline & 2-Aug & 10.63 & -2.25 & 2.51 & -1.62 & 1.98 \\
\hline & 10-Aug & 12.98 & -8.38 & -5.61 & -6.05 & 4.58 \\
\hline & 9-Sep & 5.55 & 3.72 & 11.66 & -15.37 & 4.16 \\
\hline
\end{tabular}

a,b and ${ }^{\mathrm{c}}$ From Eq.(2), Eq.(1) and Eq (3) respectively. 
Table 8

Multiple-linear regression models with DCA axes on environmental attributes using stepwise-method (DCA-SMLRMs) developed to predict soil moisture content.

\begin{tabular}{|c|c|c|c|c|c|c|}
\hline \multirow{2}{*}{$\frac{\text { Dependent variables }}{\text { Soil moisture content }}$} & \multirow[t]{2}{*}{$\% \mathrm{v} / \mathrm{v}$} & \multicolumn{5}{|c|}{ Independent variables } \\
\hline & & Intercept & DCA axis1 & DCA axis2 & DCA axis3 & DCA axis4 \\
\hline \multirow[t]{6}{*}{ Time-averaged $\left(M_{i, j}\right)$} & $0-5 \mathrm{~cm}^{\mathrm{b}}$ & 5.4 & - & 16.51 & - & - \\
\hline & $10-15 \mathrm{~cm}^{\mathrm{b}}$ & 7.11 & - & 17.33 & - & - \\
\hline & $20-25 \mathrm{~cm}^{\mathrm{b}}$ & 10.82 & - & 13.25 & -24.43 & - \\
\hline & $40-45 \mathrm{~cm}^{\mathrm{b}}$ & 15.34 & - & - & -45.85 & - \\
\hline & $70-75 \mathrm{~cm}^{\mathrm{b}}$ & 18.23 & - & - & -63.83 & - \\
\hline & $0-75 \mathrm{~cm}^{\mathrm{c}}$ & 11.4 & 11.68 & -29.04 & - & - \\
\hline \multirow[t]{10}{*}{ Layer-averaged $^{\mathrm{d}}\left(M_{i, k}\right)$} & 2-May & 11.17 & - & 28.04 & -37.73 & - \\
\hline & 13-May & 10.74 & 9.03 & 24.67 & -72.47 & - \\
\hline & 23-May & 12.28 & 6.68 & 25.8 & -66.82 & - \\
\hline & 10-Jun & 7.41 & 8.68 & 21.1 & -47.45 & - \\
\hline & 23-Jun & 10.08 & - & 12 & -37.28 & - \\
\hline & 12-Jul & 18.25 & - & - & -26.45 & - \\
\hline & 18-Jul & 11.54 & - & 12.11 & - & - \\
\hline & 2-Aug & a & a & a & a & a \\
\hline & 10-Aug & 12.27 & -8.51 & - & - & - \\
\hline & 9-Sep & 5.18 & - & 10.32 & - & - \\
\hline
\end{tabular}

- Independent variables not entered in the stepwise regression.

${ }^{\text {a }}$ None of the independent variables is entered in the stepwise regression.

b, c and ${ }^{d}$ From Eq.(2), Eq.(1) and Eq (3) respectively.

difference is not as significant as that of inter-group differences. The adjusted coefficient of determination $R_{a}^{2}$ also shows a similar trend (Fig. 2b), but less difference was detected between the entermethod models and the stepwise-method models. This is because in calculating $R_{a}^{2}$ of stepwise regression compared with enterregression, the reduced number of independent variables and the increased error tend to cancel each other out.

The mean absolute error $(M A E)$ and the root mean squared error (RMSE) measure the bias or precision of prediction model. Both indices should be as small as possible for unbiased and precise prediction. Fig. 3a depicts considerable errors for all models. The with-attribute group models appear the most unbiased or the most precise in terms of MAE and RMSE, followed by the PCA-based group models, with the DCA-based group models yielding the lowest precision. Within each group, the enter-method models are more precise than the stepwise-method models, but such withingroup differences are not as notable as those between modelgroups. Fig. 3b shows outliers as calculated with equation (8). The difference in outliers between the six methods is complicated, with, in general, with-attribute group models $<$ PCA-based group models $<$ DCA-based group models. However, the differences between the enter-method models and the stepwise-method models are small.

The dimensionless measures ( $E$ and $d$ ) provide a relative assessment of model performance. Fig. 4 indicates that the withattribute group models have the highest values (i.e., are the best) followed by the PCA-based group models and the DCA-based group models have the lowest values (i.e. are the poorest). Within each group, the enter-method models generally exhibit higher values than the stepwise-method models, however, such within-group difference is less than differences between groups. Note that the negative values of $E$ for the DCA-SMLRMs in predicting the soil moisture at $0-75 \mathrm{~cm}$ indicate, at least for these data, that the timeaveraged soil moisture estimates at $0-75 \mathrm{~cm}$ using DCA-SMLRMs are less in agreement with the observations than the observed mean value. This arises because the absolute error statistics (MAE and RMSE) are greater (Fig. 3).

Satisfactory models should make a compromise between goodness of fit and parsimony, which can be achieved by applying the Akaike information criterion (AIC) and the Schwarz or Bayesian information criterion (SIC). The model to choose is the one with the lowest value of these two criteria. Fig. 5 indicates that the values of both criteria exhibit the same trend: with-attribute group models $<$ PCA-based group models $<$ DCA-based group models. Note that for both criteria SMLRMs perform better than GMLRMs, which is the result of a great difference in the number of environmental sub-variables used in these two methods (1-6 for SMLRMs and 19 for GMLRMs) (Tables 1-4). The difference in SIC is more evident
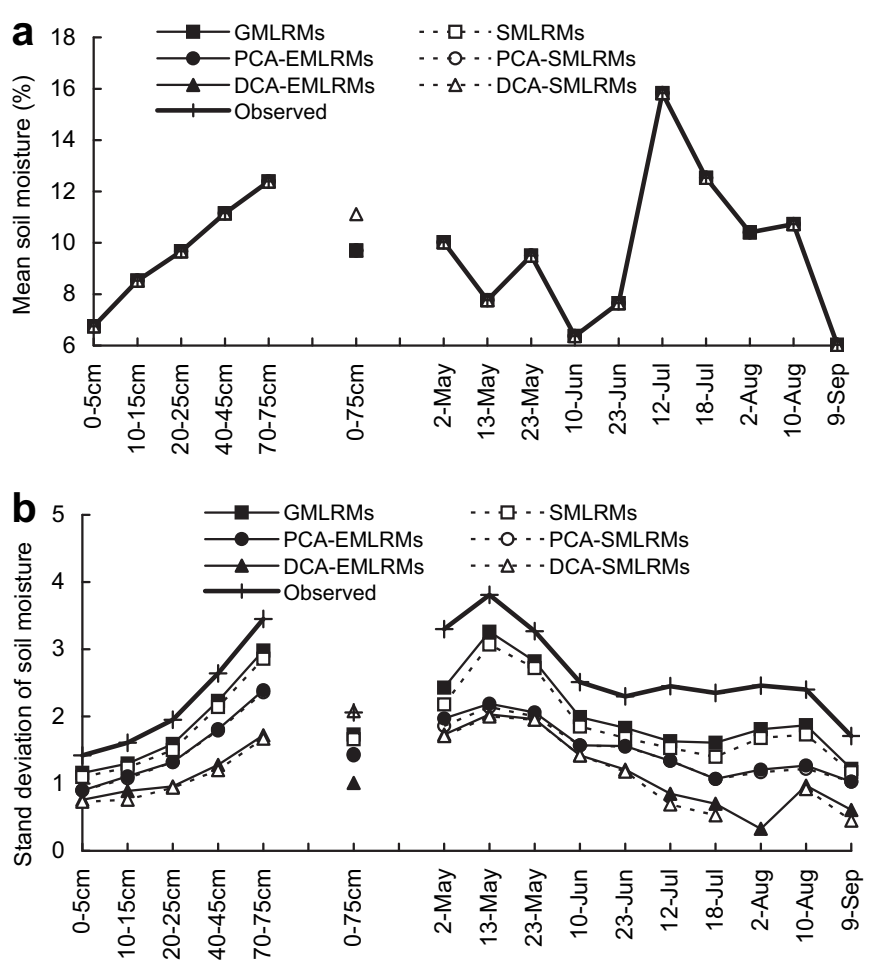

Fig. 1. Observed and predicted statistics of soil moisture content using six methods. (a) Mean; (b) Standard deviation. GMLRMs = generalized multiple-linear regression with environmental attributes; SMLRMs = multiple-linear regression with environmental variables using stepwise-method; PCA-EMLRMs = multiple-linear regression with PCA axes on environmental variables using enter-method; PCA-SMLRMs = multiple-linear regression with PCA axes on environmental variables using stepwise-method; DCAEMLRMs $=$ multiple-linear regression with DCA axes on environmental variables using enter-method; DCA-SMLRMs = multiple-linear regression with DCA axes on environmental variables using stepwise-method. 

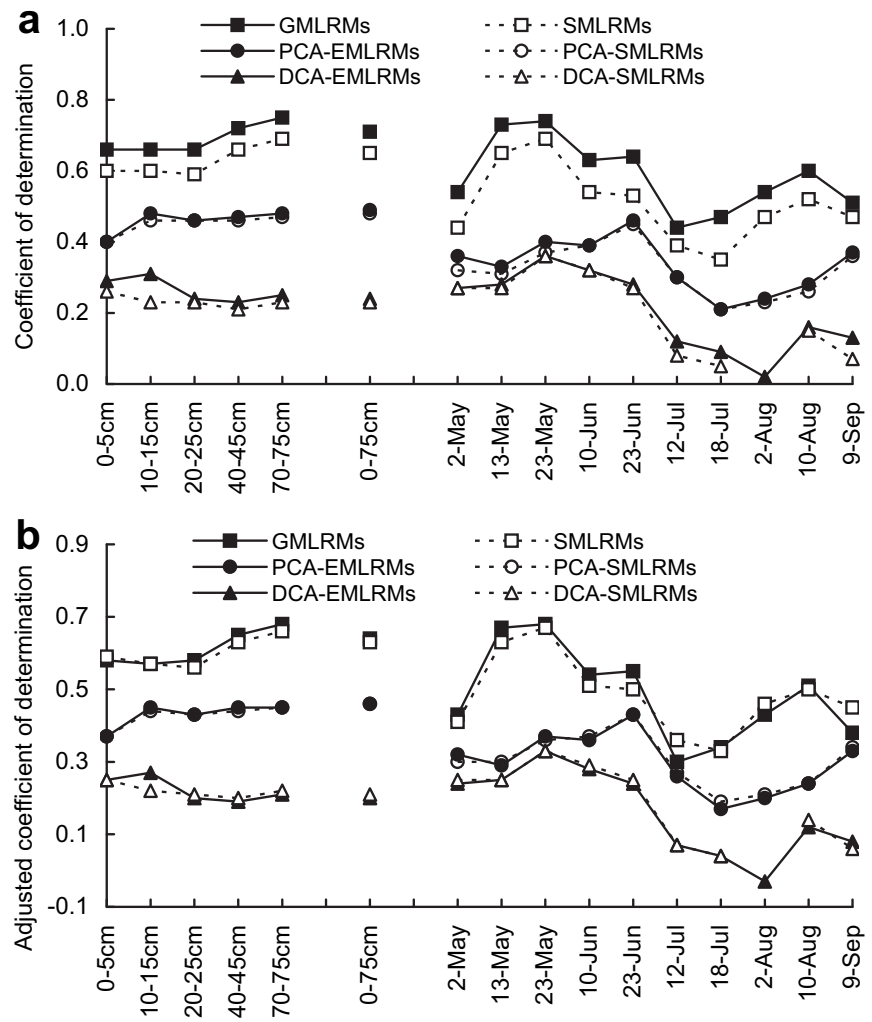

Fig. 2. Correlation-based measures of performance of models developed to predict soil moisture content using six methods. (a) Coefficient of determination $R^{2}$; (b) Adjusted coefficient of determination $R_{a}^{2}$.

than that in AIC (Fig. 5), because if $N$ is more than 8 , SIC will tend to favor models with fewer sub-variables than AIC (Webster and McBratney, 1989). However, for the PCA-based and DCA-based group models, there are only small differences in the two information criteria between the enter-method models and the stepwise-method models because the same number of environmental sub-variables are involved in both cases (19) (Appendix 3, Appendix 4, electronic version).

\section{Discussion and conclusions}

\subsection{Evaluation of spatial prediction models}

Different measures show different facets of model performance; therefore a complete assessment of model performance should include several assessment criteria, e.g. summary statistics, absolute error measures, correlation-based measures, absolute error measures, relative-error measures, etc. (Laslett et al., 1987; Legates and McCabe, 1999). In addition, information criteria can provide a satisfactory compromise between goodness of fit and parsimony (Qiu et al., 2003b; Webster and McBratney, 1989).

All 13 indices used to evaluate the multiple-linear regression models for predicting soil moisture content showed similar results. The with-attributes group models (GMLRMs and SMLRMs) were shown to be superior to the other two groups of models in predicting all aspects of soil moisture content in the Da Nangou catchment in 1999. The predictions by this group of models were nearer the observations in terms of mean, stand deviation, minimum and maximum, implying the closeness of model predictions and observations (Odeh et al., 1994; Willmott et al., 1985). This class of models could explain much more soil moisture
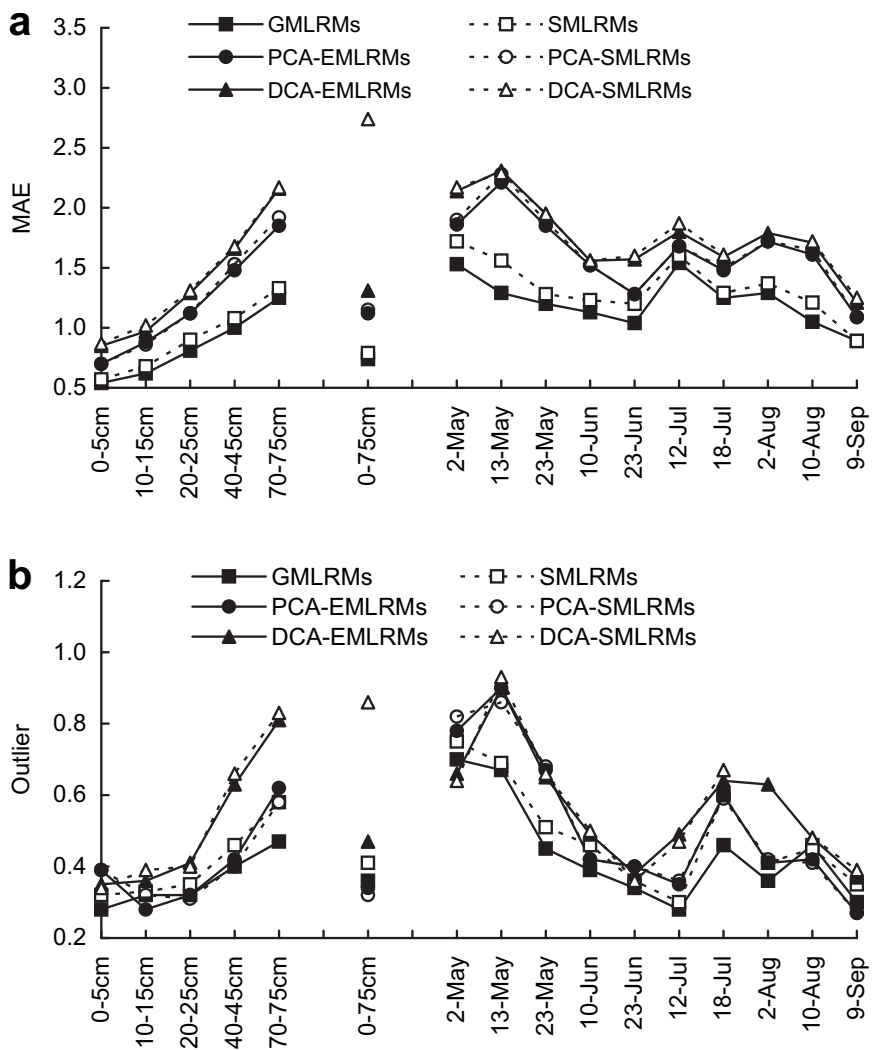

Fig. 3. Absolute error measures of performance of models developed to predict soil moisture content using six methods. (a) Mean absolute error MAE; (b) Outlier.

variation than the other two groups of models, which indicated that they are more optimum prediction models (McKenzie et al., 1991; Moore et al., 1993). This group of models also had the lowest value in prediction error (MAE and RMSE) indicating the lowest bias or the most precise prediction of soil moisture (Odeh et al., 1994; Willmott, 1981). In addition, such models had a more significant effect in minimizing the influence of outliers on prediction performance (Legates and McCabe, 1999). Furthermore, the withattribute group models had highest values in relative-error indices indicating the best agreement of model performance (Wilcox et al., 1990). Finally, these groups of models were also more economical, in terms of cost-benefit, according to AIC and SIC (Webster and McBratney, 1989).

Although the correlation-based indices (e.g. the coefficient of determination) have been used widely to evaluate the goodness of fit of models, they can not measure the precision of models (Legates and Davis, 1997; Willmott et al., 1985). These measures are oversensitive to extreme values (outliers) and are insensitive to additive and proportional differences between the model predictions and observations (Legates and Davis, 1997; Willmott, 1981). Because of these limitations, correlation-based measures can indicate that a model is a good predictor, even when it is not (Legates and McCabe, 1999). For example, the coefficient of determination was identical (0.86) for the van Bavel and Jensen-Haise methods in evaluation of potential evapotranspiration, despite the fact that other statistics and visual inspection of the time series clearly indicated the superiority of the van Bavel estimates (Legates and McCabe, 1999). If we evaluate the performance of a specific model (e.g. the GMLRMs) in prediction of soil moisture at different depths, the correlation-based indices also show opposite trends for some indices (i.e. MAE, Outlier, AIC and SIC) (Fig. 2, Fig. 3, Fig. 5). 

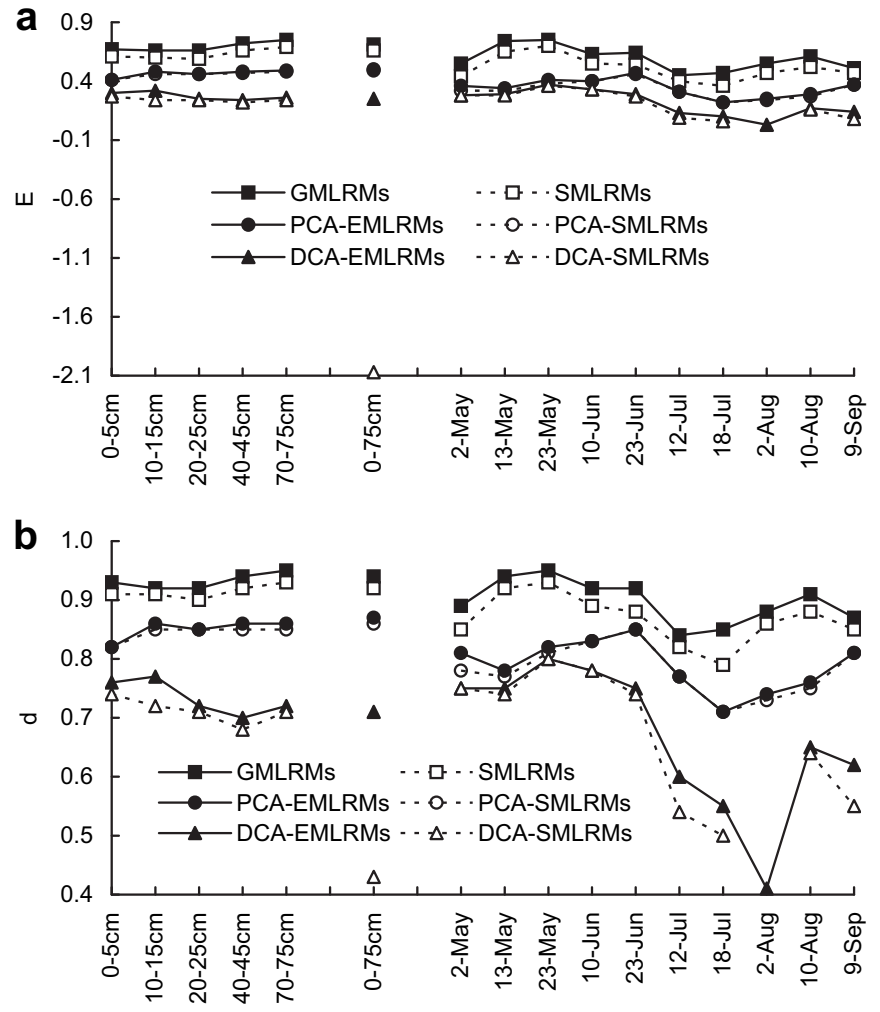

Fig. 4. Relative-error measures of performance of models developed to predict soil moisture content using six methods. (a) Coefficient of efficiency E; (b) Index of agreement $\mathrm{d}$.

However, in our comparison of spatial prediction models for soil moisture, the correlation-based indices showed similar results as other model evaluation measures (Figs. 1-5).

Therefore, the with-attributes group models (GMLRMs and SMLRMs) were robust enough to reasonably predict spatial distribution of soil moisture across the Da Nangou catchment. These multiple-linear regression models generated a higher correlation with soil moisture content than those regressions with linear (PCA) and nonlinear (DCA) transformations on environmental attributes. One explanation may be that direct linear relationships between soil moisture content and environmental attributes are very strong (McKenzie and Ryan, 1999; Qiu et al., 2001). In addition, both linear transformations and nonlinear transformations on environmental attributes that have significant reciprocal correlation may introduce much more chaos in environmental information and, in turn, diminish the performance of models (Qiu and Zhang, 1999).

There is a need to develop methods for predicting soil properties which make the best possible use of all ancillary information, particularly that which is relatively cheap to obtain (Lark, 1999). The generalized multiple-linear models provide a framework that brings separate statistical models and traditions of analysis into a single system with a common notation and unified estimation procedure (Nicholls, 1989). The main benefit for prediction of soil characteristics is the integration of explanatory variables that can also be nominal or continuous or both, therefore most of the more easily observed variables (e.g. land use type, topographic characteristics, daily meteorological attribute) can be used effectively in spatiotemporal prediction of soil moisture (Qiu et al., 2003b). McKenzie and Austin (1993) also illustrated the advantages of generalized linear models using the stepwise-method in prediction of soil characteristics in the lower Macquarie Valley, New South Wales, Australia.
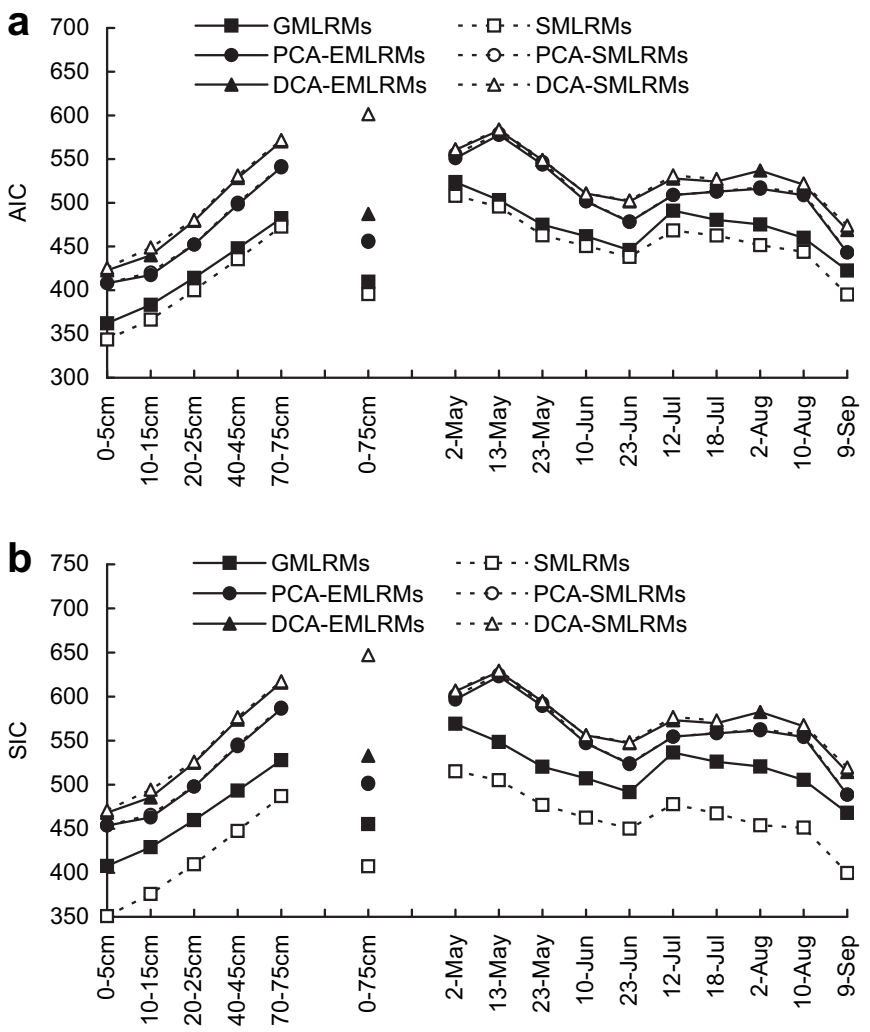

Fig. 5. Information criteria of soil moisture prediction models using six methods. (a) Akaike information criterion AIC; (b) Schwarz or Bayesian information criterion SIC.

\subsection{Gradient analysis of environmental attributes}

In summarizing the main gradient in environmental attributes, PCA was better than DCA based on the comparison of the eigenvalues (Parinet et al., 2004; Ter Braak, 1988). This implies that there are more linear than nonlinear relationships in environmental data (Camdevyren et al., 2005; Odeh et al., 1991). The first four axes of PCA could represent the main gradient in the environmental attributes at different scales, while the DCA overestimated the important factors. Thus, the PCA-based group models (PCA-EMLRMs and PCA-SMLRMs), were generally better than the DCA-based group models (DCA-EMLRMs and DCA-SMLRMs) in spatial prediction of soil moisture content. This indicates that relationships between soil moisture and environmental attributes measured are also more linear than nonlinear (Odeh et al., 1991).

In a South Australian subcatchment, the linear methods (e.g. principal component analysis) were also found to be more attractive than the nonlinear methods (i.e. canonical correspondence analyses) because interrelations among soil variables and/or between soil and the landform attributes are more linear than unimodal (Odeh et al., 1991). Wotling et al. (2000) also showed the relevance of principal component analysis of terrain in prediction of the rainfall parameter distributions. In the case of the island of Tahiti, the advantage of using the principal components (PCA) of the terrain lay in supplying in an automatic way uncorrelated and synthetic descriptors that can then be introduced simultaneously and efficiently into the stepwise regression model for prediction of the extreme rainfall intensity distributions. The main topographical features can be expressed with the 10 first principal components, each of them figuring an elementary facet of the topographical environment (Wotling et al., 2000). 


\subsection{Selection of suitable environmental variables}

Within each group of models, the enter-method models were generally better than the stepwise-method models in terms of several indices (e.g. summary statistics, $R^{2}$, adjusted $R^{2}$, MAE, RMSE, outlier, E, d). However, such within-group differences were not as significant as that of differences between groups.

According to the AIC and SIC, the SMLRMs were either the most effective or the most economical in spatial prediction of soil moisture. This type of model needed the least number of subvariables (1-6) or environmental attributes (1-4), while the other five methods required all the sub-variables (19) or environmental attributes (6) used in this study. In addition, the performance of SMLRMs was almost as effective as that of GMLRMs.

McKenzie and Ryan (1999) noted that the use of suitable environmental variables may be more important than the choice of prediction method. The stepwise regression has been used widely for prediction of environmental features since it can identify only predictive attributes that significantly improved the regression at a given level (Hontoria et al., 1999; McKenzie and Austin, 1993; Moore et al., 1993; Qiu et al., 2003b; Wotling et al., 2000). For example, Moore et al. (1993) showed that in Colorado, the stepwise regression indicated that slope and wetness index were the terrain attributes most highly correlated with surface soil attributes, while other terrain attributes (e.g. aspect, profile curvature) were not so significant. Among the 10 first principal components of topographic features, only three principal components were selected in the stepwise regression models for prediction of the rainfall statistics distributions in the island of Tahiti (Wotling et al., 2000).

\subsection{Best prediction models for application}

When applying these prediction methods, the cost-benefit performance may determine the best method, i.e., whether an increase in precision is more than compensated by the cost of additional surveys and analyses (Odeh et al., 1994; Webster and McBratney, 1989). In our study in Da Nangou catchment in 1999, if we wanted to precisely predict the soil moisture content where all the environmental variables (6) can be readily obtained, the GMLRMs would be used in preference to other methods. For example, the spatial prediction of soil moisture content based on GMLRMs could provide accurate information (Appendix 5a, electronic version) for soil erosion modeling, soil properties analysis and soil erosion control in the Da Nangou catchment (Fu et al., 2002; Qiu et al., 2004; Wang et al., 2003). However, if an increase in precision in predicting soil moisture is less than compensated by increased cost of obtaining these six environmental variables, SMLRMs may be preferable to other methods. For example, SMLRMs could provide helpful information on soil moisture content (Appendix 5b, electronic version) for land quality evaluation and for land use planning on the Loess Plateau (Qiu et al., 2003a; Wang and Qiu, 2005), although it provided less wide range of predicted soil moisture contents (Appendix 5b, electronic version) than GMLRMs (Appendix 5a, electronic version).

\section{Acknowledgements}

This study was supported by National Basic Research Program of China (2007CB407204), National Natural Science Foundation of China (30970503, 40621061, 40401001, 40501039, 90502007), Key Technologies R\&D Program of China (2006DAJ05A08, 2008BAB38B02) and INCO-DC of European Commission (ERBIC18CT970158). Thanks are expressed to the members of project team for field assistance, two anonymous reviewers for useful comments on paper and Professor Lisa M. Curran and Dr. Rudi Hessel for language revision.

\section{Appendix. Supplementary data}

Supplementary data associated with this article can be found, in the online version, at doi:10.1016/j.jaridenv.2009.08.003.

\section{References}

Bourennane, H., King, D., Chery, P., Bruand, A., 1996. Improving the kriging of a soil variables using slope gradient as external drift. European Journal of Soil Science 47, 473-483.

Brubaker, S.C., Jones, A.J., Frank, K., Lewis, D.T., 1994. Regression models for estimating soil properties by landscape position. Soil Science Society of America Journal 58, 1763-1767.

Camdevyren, H., Demyr, N., Kanik, A., Keskyn, S., 2005. Use of principal component scores in multiple linear regression models for prediction of chlorophyll-a in reservoirs. Ecological Modelling 181, 581-589.

Fu, B.J., Qiu, Y., Wang, J., Chen, L.D., 2002. Effect simulations of land use change on the runoff and erosion for a gully catchment of the Loess Plateau, China. Acta Geographica Sinica 57, 717-722. Chinese, with English abstract.

Fu, B.J., Chen, L.D., 2000. Agricultural landscape spatial pattern analysis in the semi-arid hill area of the Loess Plateau, China. Journal of Arid Environments 44, 291-303.

Fu, B., Gulinck, H., 1994. Land evaluation in area of severe erosion: the Loess Plateau of China. Land Degradation and Rehabilitation 5, 33-40.

Fu, B.J., 1989. Soil erosion risk and its control in the Loess Plateau of China. Soil Use and Management 5, 76-82.

Fu, B.J., 1991. Land evaluation in the Loess Plateau of northern Shannxi province. Journal of Soil and Water Conservation 5, 1-7. Chinese, with English abstract.

Fu, B.J., Chen, L.D., Ma, K.M., Zhou, H.F., Wang, J., 2000. The relationships between land use and soil conditions in the hilly area of the Loess Plateau in northern Shaanxi, China. Catena 39, 69-78.

Grayson, R.B., Western, A.W., 1998. Towards areal estimation of soil water content from point measurements: time and space stability of mean response. Journal of Hydrology 207, 68-82.

Hessel, R., Jetten, V., Liu, B.Y., Zhang, Y., Stolte, J., 2003. Calibration of the LISEM model for a small Loess Plateau catchment. Catena 54, 235-254.

Hontoria, C., Rodriguez-Murillo, J.C., Saa, A., 1999. Relationships between soil organic carbon and site characteristics in Peninsular Spain. Soil Science Society of America Journal 63, 614-621.

King, D., Bourennane, H., Isambert, M., Macaire, J.J., 1999. Relationships of the presence of a non-calcareous clay-loam horizon to DEM attributes in a gently sloping area. Geoderma 89, 95-111.

Knotters, M., Brus, D.J., OudeVoshaar, J.H.O., 1995. A comparison of kriging, cokriging and kriging combined with regression for spatial interpolation of horizon depth with censored observations. Geoderma 67, 227-246.

Lark, R.M., 1999. Soil-landform relationships at within-field scales: an investigation using continuous classification. Geoderma 92, 141-165.

Laslett, G.M., McBratney, A.B., Pahl, P.J., Hutchinson, M.F., 1987. Comparison of several spatial prediction methods for soil pH. European Journal of Soil Science 38, 325-341.

Legates, D.R., Davis, R.E., 1997. The continuing search for an anthropogenic climate change signal: limitations of correlation-based approaches. Geophysical Research Letters 24, 2319-2322.

Legates, D.R., McCabe Jr., G.J., 1999. Evaluating the use of "goodness-of-fit" measures in hydrologic and hydroclimatic model validation. Water Resource Research 35, 233-242.

Manrique, L.A., Jones, C.A., Dyke, P.T., 1991. Predicting soil water retention characteristics from soil physical and chemical properties. Communications in Soil Science and Plant Analysis 22, 1847-1860.

McKenzie, N.J., MacLeod, D.A., 1989. Relationships between soil morphology and soil properties relevant to irrigated and dryland agriculture. Australian Journal of Soil Research 27, 235-258.

McKenzie, N.J., Austin, M.P., 1993. A quantitative Australian approach to medium and small scale surveys based on soil stratigraphy and environmental correlation. Geoderma 57, 329-355.

McKenzie, N.J., Ryan, P.J., 1999. Spatial prediction of soil properties using environmental correlation. Geoderma 89, 67-94.

McKenzie, N.J., Smettem, K.R.J., Ringrose-Voase, A.J., 1991. Evaluation of methods for inferring air and water properties of soil from field morphology. Australian Journal of Soil Research 29, 587-602.

Montgomery, D.C., Peck, E.A., Vining, G.G., 2006. Introduction to Linear Regression Analysis, fourth ed. John Wiley \& Sons, Inc., Hoboken, New Jersey.

Moore, I.D., Gessler, P.E., Nielsen, G.A., Peterson, G.A., 1993. Soil attribute predictions using terrain analysis. Soil Science Society of America Journal 57, 443-452.

Nash, J.E., Sutcliffe, J.V., 1970. River flow forecasting through conceptual models: I. A discussion of principles. Journal of Hydrology 10, 282-290.

Nicholls, A.O., 1989. How to make biological surveys go further with generalized linear models. Biological Conservation 50, 51-75.

Odeh, I.O.A., Chittleborough, D.J., McBratney, A.B., 1991. Elucidation of soil-landform interrelationships by canonical ordination analysis. Geoderma 49, 1-32.

Odeh, I.O.A., McBratney, A.B., Chittleborough, D.J., 1994. Spatial prediction of soil properties from landform attributes derived from a digital elevation model. Geoderma 63, 197-214. 
Parinet, B., Lhote, A., Legube, B., 2004. Principal component analysis: an appropriate tool for water quality evaluation and management-application to a tropical lake system. Ecological Modelling 178, 295-311.

Qiu, Y., Zhang, J.T., 1999. Quantitative analysis to the gradients in space and time of natural plant communities in Bashuigou catchment of the Guandi Mountain, Shanxi Province, China. Chinese Journal of Applied and Environmental Biology 5, 113-120. Chinese, with English abstract.

Qiu, Y., Fu, B., Wang, J., Chen, L., 2001. Spatial variability of soil moisture content and its relation to environmental factors in a semi-arid gully catchment of the Loess Plateau, China. Journal of Arid Environments 49, 723-750.

Qiu, Y., Fu, B.J., Wang, J., Chen, L.D., 2003a. Spatio-temporal distribution of land use in relation to topography in a gully catchment of the Loess Plateau, China. Journal of Natural Resources 18, 20-29. Chinese, with English abstract.

Qiu, Y., Fu, B., Wang, J., Chen, L., 2003b. Spatiotemporal prediction of soil moisture content using multiple-linear regression in a small catchment of the Loess Plateau, China. Catena 54, 173-195.

Qiu, Y., Fu, B.J., Wang, J., Chen, L.D., 2004. Spatiotemporal variability of the soil erosion and its relations to the influencing factors on the Loess Plateau, China. Acata Ecologica Sinica 24, 1871-1878. Chinese, with English abstract.

Song, G., Li, L., Guo, F., Zhao, M., 1989. Land classification of experiment and exemplary areas on the Loess Plateau. Memoir of Northwestern Institute of Soil and Water Conservation, Academia Sinica and Ministry of Water Resources, China 10,1-13. Chinese, with English abstract.

Steele, B.M., Reddy, S.K., Nemani, R.R., 2005. A regression strategy for analyzing environmental data generated by spatio-temporal processes. Ecological Modelling 181, 93-108.

Stein, A., Van Dooremolen, W., Bouma, J., Bregt, A.K., 1988. Cokriging point data on moisture deficit. Soil Science Society of America Journal 52, 1418-1423.

Ter Braak, C.J.F., 1988. CANOCO: A FORTRAN Program for Canonical Community Ordination by Partial Detrended Canonical Correspondence Analysis and Redundancy Analysis. version 2.1. Agricultural Mathematics Group, Wageningen.
Wang, J., Qiu, Y., 2005. Review on spatial variability and scale effects of land quality Progress in Geography 24, 28-35. Chinese, with English abstract.

Wang, J., Fu, B., Qiu, Y., Chen, L., 2003. The effects of land use and its patterns on soil properties in a small catchment of the Loess Plateau. Journal of Environmental Sciences 15, 263-266.

Wang, J., Fu, B., Qiu, Y., Chen, L., Wang, Z., 2001. Geostatistical analysis of soil moisture variability ion Da Nangou catchment of Loess Plateau, China. Environmental Geology 41, 113-120.

Webster, R., Butler, B.E., 1976. Soil survey and classification studies at Ginninderra. Australian Journal of Soil Research 14, 1-24.

Webster, R., McBratney, A.B., 1989. On the Akaike Information Criterion for choosing models for variograms of soil properties. European Journal of Soil Science 40, 493-496.

Webster, R., 1985. Quantitative spatial analysis of soil in the field. Advances in Soil Science 3, 1-70

Western, A.W., Bloschl, G., Grayson, R.B., 1998. Geostatistical characterisation of soil moisture patterns in the Tarrawarra catchment. Journal of Hydrology 205, 20-37.

Western, A.W., Grayson, R.B., Bloschl, G., Willgoose, G.R., McMahon, T.A., 1999 Observed spatial organization of soil moisture and its relation to terrain indices. Water Resource Research 35, 797-810.

Wilcox, B.P., Rawls, W.J., Brakensiek, D.L., Wight, J.R., 1990. Predicting runoff from rangeland catchments: a comparison of two models. Water Resource Research 26, 2401-2410.

Willmott, CJ. 1981. On the validation of models. Physical Geography 2, 184-194.

Willmott, C.J., Ackleson, S.G., Davis, R.E., Feddema, J.J., Klink, K.M., Legates, D.R. O'Donnell, J., Rowe, C.M., 1985. Statistics for the evaluation and comparison of models. Journal of Geophysical Research 90, 8995-9005.

Wotling, G., Bouvier, Ch., Danloux, J., Fritsch, J.M., 2000. Regionalization of extreme precipitation distribution using the principal components of the topographica environment. Journal of Hydrology 233, 86-101.

Yates, S.R., Warrick, A.W., 1987. Estimating soil water content using cokriging. Soil Science Society of America Journal 51, 23-30. 